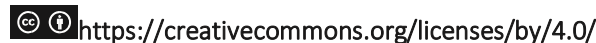

ARTIGO

\title{
IDEOLOGIA E EDUCAÇÃO NA PERSPECTIVA DE LOUIS ALTHUSSER
}

\author{
DEBORA KLIPPEL FOFANO ${ }^{1}$ \\ ORCID: https://orcid.org/ 0000-0002-5825-1887 \\ HILDEMAR LUIZ RECH ${ }^{2}$ \\ ORCID: https://orcid.org/ 0000-0003-3713-7564
}

\begin{abstract}
RESUMO: Abordar a ideologia exige a capacidade de adentrar diferentes perspectivas contemporâneas dessa temática, visto que este fenômeno adquire configurações crescentemente mais complexas atualmente. Escolhemos o filósofo esloveno Slavoj Žižek como articulador da miríade de conceitos sobre a ideologia e, tomamos por fundamento a teoria de Althusser e seus conceitos de Ideologia e Aparelhos Ideológicos de Estado. Ao tensionar reflexivamente os conceitos visualizamos como a ideologia atua, quais seus elementos fulcrais. Para tanto, dentro da tradição filosófica, aproximamos a perspectiva do aparelho de Althusser, aos conceitos de positividade de Hegel, dispositivo de Foucault e Agamben e "grande Outro" de Lacan, como mecanismos de controle e alienação do sujeito. Desse modo, compreenderemos melhor a crítica ao "Aparelho Ideológico Escolar" e seus desdobramentos no que diz respeito à educação brasileira. Nesse sentindo, percebemos também os limites do pensamento de Althusser, no que se refere ao processo de subjetivação e dessubjetivação, e de como o processo de educação é atravessado por variados fenômenos e acontecimentos, uma vez que pode estar em permanente transformação, pois nunca é completo, como o sujeito também nunca é.
\end{abstract}

Palavras-chave: Ideologia, Aparelho Ideológico, Subjetivação e Educação.

\section{IDEOLOGY AND EDUCATION FROM THE PERSPECTIVE OF LOUIS ALTHUSSER}

\begin{abstract}
Approach the ideology requires the ability to going inside to the contemporary perspectives of this theme, since this phenomenon acquires increasingly more complex configurations today. We chose the Slovenian philosopher Slavoj Žižek as articulator of the myriad of concepts about ideology and, we takes as a fundamental bases the Althusser's theory and its concepts of Ideology and its "Ideological State Apparatus". When tensioning reflexively these concepts we visualize how ideology acts and what are crucial elements. To get this aim, within the philosophical tradition, we approach, beyond the perspective of Althusser's apparatus, the concepts of positivity of Hegel, dispositive of Foucault and Agamben, and "great Other" of Lacan, as control and alienation of the subject. Thus, we will better understand the criticism of the "School Ideological Apparatus" and its developments concerning to Brazilian education. In this sense, we also perceive the limits of Althusser's thinking, with regard to the process of subjectivation and dessubjectivation, and about how the education process can be full of events, since it can be in permanent transformation because it is never complete, as well as the subject is never is.
\end{abstract}

\footnotetext{
${ }^{1}$ Universidade Federal do Ceará (UFC). Fortaleza, CE, Brasil. < deborafofano@hotmail.com>

${ }^{2}$ Universidade Federal do Ceará (UFC). Fortaleza, CE, Brasil. < hluizrech@gmail.com> Educação em Revista|Belo Horizonte|v.37|e232216|2021
} 
Key-words: Ideology, Ideological Apparatus, Subjectivation and Education.

\section{IDEOLOGÍA Y EDUCACIÓN DESDE LA PERSPECTIVA DE LOUIS ALTHUSSER}

RESÚMEN: Abordar la ideología requiere la capacidad de entrar en diferentes perspectivas contemporáneas de este tema, ya que este fenómeno adquiere configuraciones cada vez más complejas hoy en día. Elegimos al filósofo esloveno Slavoj Žižek como articulador de la miríada de conceptos sobre la ideología y, tomamos la base la teoría de Althusser y sus conceptos de ideología y Aparato Estado ideológico. Al tensar reflexivamente los conceptos visualizamos cómo actúa la ideología, cuáles son sus elementos centrales. Para ello, dentro de la tradición filosófica, abordamos la perspectiva del aparato de Althusser, a los conceptos de positividad del dispositivo Hegel, Foucault y Agamben y del "gran Otro" de Lacan, como mecanismos de control y alienación del sujeto. Por lo tanto, entenderemos mejor la crítica del "Aparato Ideológico Escolar" y sus desarrollos con respecto a la educación brasileña. En este sentimiento, también percibimos los límites del pensamiento de Althusser, con respecto al proceso de subjetivación y dessubjetivación, y cómo el proceso educativo es atravesado por diversos fenómenos y eventos, ya que puede ser permanente transformación, porque nunca está completa, ya que el sujeto nunca lo es tampoco.

Palabras clave: Ideología. Aparato Ideológico. Subjetivación y Educación.

\section{INTRODUÇÃO}

A ideologia carrega a noção imanente de doutrina, conjunto de ideias, crenças, conceitos e parece estar determinada a convencer de uma veracidade, quando, porém, serve a determinado subterfúgio de poder. Uma matriz ideológica é rotineiramente construída de forma aparentemente desconectada de sua condição material, e mesmo assim persiste em regular a relação entre aquilo que há de mais sutil e básico na vida até os grandes ideais que dominam e motivam as massas. Vemos assim uma multidão que canta junto com o poeta do rock popular brasileiro: "Ideologia, eu quero uma para viver". (Agenor de Miranda Araújo Neto, Cazuza, nasceu no Rio de Janeiro e viveu entre 1958 -1990, foi compositor, poeta e letrista brasileiro). Ideologia (1988), além de música é o título do álbum. A capa do disco traz símbolos e valores diferentes, provocando uma reflexão sobre o estado da situação política e cultural do Brasil na década de 1980. Em uma breve análise da música podemos perceber a expressão da confusão e vazio da sociedade, pessoas dessubjetivadas que clamam por valores para viver.

Nesse aspecto, segundo a tradição dialética, podemos dizer que a ideologia é imanente, situando-se entre o transparente e o opaco, o material e o imaterial, o possível e o impossível, e até mesmo parece estar presente em tudo aquilo que aponta para além de uma saída dualista; a ideologia opera uma articulação importante que atinge tudo e todos e em todo lugar. Esse primeiro apontamento, no entanto, parece ser lugar comum dentre os pensadores e estudiosos da filosofia. Como então construir uma perspectiva que nos permita atravessar o óbvio e sair de uma discussão já desgastada sobre a ideologia? Como ir em direção a uma leitura mais interessante sobre o fundamento da ideologia? Propomos no presente artigo desenvolver uma modalidade de crítica que pretende discernir sobre a tendenciosidade não reconhecida na realidade oficial, através de suas rupturas, lacunas e lapsos. Em vez de avaliar diretamente a adequação ou a veracidade das diferentes noções de ideologia, desejamos compreender a multiplicidade de determinações como um indicador de diferentes situações concretas. Procedendo assim, já anunciamos uma leitura atravessada pela psicanálise lacaniana e uma transposição históricodialética hegeliana do problema para sua própria solução.

Essa forma de proceder foi pensada pelo filósofo esloveno Slavoj Žižek (Liubiana1949 -) e pode ser compreendida em algumas das suas obras como Visão em Paralaxe (2008) e Menos que nada (2012). Žižek é filósofo, psicanalista e um dos principais teóricos contemporâneos, transita em diversas áreas do conhecimento que vão do cinema a cafés e, sob influência de pensadores, tais como Marx (Tréveris, 1918 - Londres, 1883) e Lacan (Paris, 1901 - Paris, 1981), efetua uma contundente crítica cultural e política da pós-modernidade. Žižek atua nessa pesquisa como articulador da diversidade de pensamentos sobre a 
ideologia, apontando e contorcendo os conceitos para que possam aparecer menos desgastados, dado ser este um tema já tão examinado.

\footnotetext{
A ideologia pode designar qualquer coisa, desde uma atitude contemplativa que desconhece sua dependência em relação à realidade social, até um conjunto de crenças voltado para ação; desde o meio essencial em que os indivíduos vivenciam suas relações com a estrutura social até as ideias falsas que legitimam um poder político dominante. Ela parece surgir exatamente quando tentamos evitá-la e deixa de aparecer onde claramente se esperaria que existisse. Quando um processo é denunciado como "ideológico por excelência", pode se ter certeza de que seu inverso não é menos ideológico. (ŽIŽEK, 1996, p. 09).
}

Um ponto de partida interessante é perceber que a própria crítica da ideologia implica uma espécie de lugar privilegiado, como se a crítica à ideologia fosse isenta das agitações da vida social, que facultaria a esse sujeito crítico, diante do real, a incrível capacidade de perceber o mecanismo oculto que regula a visibilidade e a invisibilidade social. Essa imagem de oferecer uma crítica à ideologia de um ponto de vista supostamente neutro já não é, em si, ideológica?

Diante dessas questões, diversos filósofos contribuíram para uma investigação possível da ideologia: Marx, ao traçar apontamentos importantes para uma crítica da ideologia contemporânea que se afaste de um projeto ingênuo; A perspectiva de Althusser (Argélia, 1918 - La Verrière, 1990) e os seus Aparelhos Ideológicos de Estado e alguns outros dispositivos semelhantes; Lacan ao tensionar o conceito da ideologia com seu cerne na fantasia. Esses pensadores aparecem para Žižek de forma interconectada e vamos nos remeter a eles, mas como tratar de ideologia de forma tão ampla não cabe nessa exposição, vamos nos remeter à ideologia em sua alteridade-externalização, momento dialetizado de forma inovadora pela noção althusseriana de Aparelhos Ideológicos de Estado (AIE). Essa compreensão prática da ideologia também encontra sua realização nos dispositivos e noutras formas de articulação mecânica da ideologia no que tange à realidade em sua forma eficiente enquanto agencia práticas cotidianas que podem culminar em exercícios totalitários.

Sendo assim nosso esforço, apesar de constituir um diálogo em torno de uma constelação de pensadores e conceitos, se concentra na compreensão da obra Ideologia e Aparelhos ideológicos de Estado, de Louis Althusser (1980), pois esta estrutura o tema da ideologia tendo como base a dialética abordada através de uma matriz radicalmente diferente, a (sobre)determinação estrutural. Veremos como a existência material das ideologias nas práticas, rituais e instituições ideológicas se consolidam.

\section{A IDEOLOGIA PARA ALTHUSSER}

O filósofo francês de origem argelina foi combatente durante a Segunda Guerra e em 1948 filiou-se ao Partido Comunista. Tinha um pouco mais de 40 anos quando começou a ter grande reconhecimento por seu pensamento. Suas preocupações iniciais versavam sobre a relação entre cristianismo e marxismo, enfatizando a crítica de Hegel no pensamento de Marx (ALTHUSSER, 1979). Althusser ministrava seminários de estudos marxistas e já se desenhava como um dos intérpretes contemporâneos mais influentes do autor de "O Capital". Partilhou seus conhecimentos e reflexões com grandes pensadores da época, como Étienne Balibar, Yves Duroux, Jacques Rancière, Jean-Claude Milner e Allain Badiou.

Althusser foi um dos pensadores do século XX que mais contribui às análises filosóficas de cunho marxista, fazendo forte crítica ao economicismo e humanismo atribuídos à teoria. Ele procurou não se deter apenas na crítica, mas contribuir para ultrapassar determinadas análises políticas, em direção ao diálogo profícuo com a psicanálise e outras tendências da filosofia contemporânea. A compreensão da ideologia como uma teoria genética de ideias remete a Destutt de Tracy (Paris 1754 - Paris 1836), mas, segundo Althusser (1980), foi Marx que na Ideologia Alemã (2007), ao retomar o termo, atribuiu a ele uma nova e revigorada compreensão, pois entendeu a ideologia como sistema das ideias, das representações que domina o espírito do homem ou de um grupo social.

Para Althusser (1980), é de extrema importância desenvolver uma teoria das ideias, lembrando que qualquer que seja, ela sempre repousa sobre a história das formações sociais e suas 
consequências. Entretanto, ele nos alerta para o fato de não ser possível uma teoria das ideologias em geral. As múltiplas ideologias só podem ser compreendidas em sua particularidade já que têm a partir das relações regionais e de classes uma história própria. Em cada circunstância concreta, a ideologia opera de modo diferente, demandando a impossibilidade prática de se pensar em uma teoria das ideologias, no sentido de uma sintetização histórica. No POST-SCRIPITUM da obra Ideologia e Aparelhos Ideológicos de Estado, Althusser (1980) esclarece que só do ponto de vista das classes, ou seja, da luta de classes é que se pode perceber as ideologias, porque aí é que se constata a realização das ideologias dominantes, e se compreende de onde vêm as ideologias que estruturam os Aparelhos Ideológicos de Estado. Os AIE não são a realização da ideologia em geral, nem sequer a realização sem conflitos da ideologia da classe dominante.

Žižek (2013) nos alerta a respeito dessa lição de Althusser sobre a "luta de classes", pois esta, paradoxalmente, precede as classes como grupos sociais determinados. Cada determinação e posição de classes já é um próprio efeito da "luta de classes". Assim, classes não são categorias da realidade social positiva, partes do corpo social, mas uma categoria do registro do Real (em oposição à realidade, enquanto categoria da simbolização); de uma luta política que atravessa todo o corpo social impedindo sua "totalização". E ainda, Žižek (2012) admite que a luta de classes é outro nome para o fato de que "a sociedade não existe", não como ordem positiva do ser.

Não obstante, para Althusser, o que mais importa é desenvolver uma teoria da ideologia no singular, enquanto conceito, seja ela uma teoria da ideologia em geral ou uma teoria da ideologia em particular, visto que cada uma expressa em seu bojo uma posição de classe, uma tópica. Para pensar a teoria da ideologia em geral, Althusser retoma Marx na Ideologia Alemã, mas procura ultrapassá-lo socorrendo-se de conceitos psicanalíticos. Assim, começa a construir sua tese de que a ideologia em geral não tem história:

\footnotetext{
$\mathrm{Na}$ Ideologia Alemã, esta fórmula figura num contexto francamente positivista. A ideologia é então concebida como pura ilusão, puro sonho, isto é, nada. Toda a sua realidade está fora de si própria. É pensada como uma construção imaginária cujo estatuto é exatamente semelhante ao estatuto teórico do sonho nos autores anteriores a Freud. (ALTHUSSER, 1980, p. 72).
}

A tese que Althusser sustenta estabelece a noção de ideologia que se distancia da teoria marxiana e dialoga com Freud (ALTHUSSER, 2000) na medida que se alinha com a proposição segundo a qual o inconsciente é eterno, isto é, não tem história. "Ser eterno, não quer dizer transcendente a toda história, mas omnipresente, trans-histórico, portanto, imutável na sua forma ao longo da história." (ALTHUSSER, 1980, p. 75).

Se a ideologia, em geral, não tem história, podemos entender que ela atua na base estrutural da sociedade de modo infinito e universal em sua essência. Ao pensarmos que os objetos representados pela ideologia são uma ilusão, somos obrigados a admitir que de alguma forma eles fazem alusão à realidade. Portanto, bastaria interpretar essa ilusão para encontrar, sob a sua representação, a realidade do mundo material. O problema é que na realidade prática as coisas não se desenrolam dessa maneira. A percepção elementar, a de que uma simples ilusão da realidade é criada pelos sujeitos para representar as ideias, cai por terra, porque a ideologia que opera a deformação imaginária das relações que existem é a representação das relações que dela derivam.

\footnotetext{
Não são as condições de existências reais, o seu mundo real, que os homens representam na ideologia, mas é a relação dos homens com estas condições de existência que lhes é representada na ideologia. É esta relação que está no centro de toda a representação ideológica, portanto imaginária do mundo real. Toda ideologia representa, na sua deformação necessariamente imaginária, não as relações de produção existentes, mas antes de mais nada a relação imaginária dos indivíduos com as relações de produção e com as relações que delas derivam. Na ideologia, o que é representado não é sistema das relações reais que governam a existência dos indivíduos, mas a relação imaginária destes indivíduos com as relações reais em que vivem. (ALTHUSSER, 1980 , p. 81 e 82$)$.
}

A ideologia, na perspectiva Althusseriana, não é fundamentalmente "uma questão de 'ideias': é uma estrutura que se impõe a nós, sem necessariamente ter que passar pela consciência." (TEIXEIRA, 
2005, p. 75). Podemos ver aqui uma contribuição diferenciada de Althusser em relação à ideologia, já que a ideologia é concebida "como algo no estado indeterminado de não ser verdadeiro, mas que é, no entanto, necessariamente vital.” (TEIXEIRA, 2005, p.75).

A ideologia não se apresenta na realidade de modo teórico, mas em sua materialidade, sua existência é concreta e se manifesta através de um aparelho. Ela afeta os indivíduos, sujeitos que vivem em uma ideologia, isto é, que têm uma representação do mundo, seja ela religiosa, moral, jurídica etc. É nesse sentido que a deformação imaginária depende da relação imaginária com as condições materiais de sua existência. Podemos afirmar que a relação imaginária do indivíduo com sua condição de classe é, em si, calcada em uma existência material. Para Althusser,

As ideias desaparecem enquanto tais (enquanto dotadas de uma existencia ideal, espiritual), na medida em que ficou claro que a existência destas se inscrevia nos atos das práticas reguladas pelos rituais definidos em última instancia por um aparelho ideológico. Surge assim que o sujeito age enquanto é agido pelo seguinte sistema (enunciado na sua ordem de determinação real): ideologia existindo num aparelho ideológico material, prescrevendo práticas materiais, reguladas por um ritual material, as quais existem nos atos materiais de um sujeito agindo em consciência sua a sua crença. (ALTHUSSER, 1980, p. 90).

Essa compreensão, inédita até então, retira a ideologia do plano das ideias e lhe impõe uma materialidade, remontando noções significativas para a compreensão dialética entre ideologia no plano teórico e seu aspecto na realidade material, pois encontra nas noções de sujeito, consciência, crença e atos, repercussões que permitem a Althusser (1980) enunciar duas teses conjuntas: "Só existe prática através e sob uma ideologia" e "Só existe ideologia através do sujeito e para sujeitos". É nesse aspecto que Althusser concorda com Lacan (2005) na impossibilidade de ter acesso às "condições reais da existência", já que estamos presos à linguagem e nossa dimensão simbólica que conduz nossa experiência no plano da realidade material. Entretanto, se abordarmos de forma rigorosa a sociedade, nos aproximando de uma compreensão menos ingênua de como somos inscritos na ideologia, por processos complexos de reconhecimento, poderemos compreender melhor como a ideologia atua socialmente.

Em acordo com essa perspectiva, não podemos perder de vista que, para Althusser, a ideologia também é fundamental em termos de constituição do sujeito. Segundo Silva (2009), a função da ideologia é constituir indivíduos concretos em sujeitos. Desse modo, o processo de interpelação ideológica a que os sujeitos são submetidos é fundamental para a constituição de sua teoria da ideologia.

Tal processo é reconhecível e acontece na medida que o indivíduo que crê em algo se revela como possuidor de uma consciência na qual estão contidas as ideias da sua crença. Através de um dispositivo conceitual, estabelecido pelo próprio sujeito, desdobra-se na materialidade um determinado comportamento. Decorrente disso, o indivíduo que crê se comporta conforme determinadas práticas reguladas pelos aparelhos ideológicos, dos quais dependem as ideias às quais o sujeito escolheu livre $\mathrm{e}$ conscientemente. Nesse aspecto, entendemos, juntos com o filósofo, que o sujeito passa a crer nas ideias que a sua consciência aceitou livremente, por isso age segundo as suas ideias e inscreve nos atos da sua prática material as suas próprias ideias de sujeitos livres. "A ideologia da ideologia reconhece, portanto, apesar de sua deformação originária, que as ideias dos sujeitos humanos existem em seus atos." (ALTHUSSER, 1980, p. 86 e 87).

É nesse processo que a ideologia oferece suporte aos atos inseridos em práticas concretamente reguladas. Se considerarmos que no sujeito a existência das ideias em sua crença é material, as suas ideias são atos materiais inseridos em práticas materiais, assim, em último aspecto, a ideologia é a prática gerenciadora de rituais materiais. É nesse processo que o termo ideia vai se tornando cada vez mais abstrato, até se tornar inteiramente descolado da realidade material a que ela se refere. Nesse artifício, a ideia passa a ficar implícita nos atos, não desaparecendo totalmente ela vai se tornando transparente, subsistindo de modo permanente e eficiente nos termos: sujeito, consciência, crença e atos, que não são materiais fisicamente, mas se mostram evidentes e acontecendo em termos objetivos nos rituais através dos aparelhos ideológicos. Uma das formas mais elaboradas desse procedimento é a interpelação ideológica que desenvolveremos a seguir. 


\section{A IDEOLOGIA INTERPELA INDIVÍDUOS EM SUJEITOS}

Segundo Althusser (1980), a substituição paulatina das ideias pela materialidade corresponde a uma remodelação bastante peculiar, tendo sua estrutura calcada no sujeito enquanto aquele que opera a deformação imaginária na sua relação com a realidade. Por isso, a contribuição fundamental do autor está em estruturar categoricamente a ideologia como interpelação de indivíduos como sujeitos, implicando que só existe ideologia pelos sujeitos e para sujeitos, ao mesmo tempo que a ideologia constitui indivíduos concretos em sujeitos. Sujeito e ideologia estão dialeticamente imbricados na medida que um constitui o outro. "É neste jogo, de dupla constituição que consiste o funcionamento de toda ideologia, pois que a ideologia não é mais que o próprio funcionamento nas formas materiais da existencia deste funcionamento." (ALTHUSSER, 1980, p. 94).

Esse jogo dialético que afirma a duplicidade em que o sujeito é atravessado pela ideologia, ao mesmo tempo que é o reprodutor dela, é pedra de toque para entender os fenômenos da materialidade ideológica. Reconhecer esse fenômeno é importante, pois esse processo se torna cada vez mais encoberto, o que paradoxalmente evidencia o problema do escamoteamento que a ideologia produz, ao mesmo tempo que encobre esse mesmo movimento. Esse fenômeno ocorre porque um dos efeitos da ideologia é a denegação: a ideologia nunca é reconhecida como ideológica, é preciso estar fora da ideologia, no conhecimento científico, para poder afirmar que algo é ideológico ou mesmo reconhecer, caso excepcional, que se está na ideologia; o que percebemos até aqui ser um procedimento inteiramente frágil e cínico. Segundo Peter Sloterdijk (2012), o modo dominante de funcionamento da ideologia contemporânea é o da "razão cínica". Ela é fundada no paradoxo de uma falsa consciência esclarecida, que sabe da sua falsidade, mas não abdica dela.

Como Althusser (1970) afirma, a ideologia em geral é eterna, portanto, não tem exterior, ela interpela desde seu surgimento os indivíduos como sujeitos, a todo tempo, desde o nascimento a ideologia cerca o indivíduo, o assedia e assim o transforma em sujeito. "A interpelação nunca falha à pessoa visada: mediante chamamento verbal, o assobio, o interpelado reconhece sempre que era a ele que interpelavam." (ALTHUSSER, 1980, p. 99-100). O sujeito, na perspectiva de Althusser, é tanto sujeito da ação, das práticas, como também um sujeito submetido a outro Sujeito. Nesse aspecto, Althusser (1980) requisita "O estádio do espelho como formador da função do eu", de Lacan (1998). Segundo Teixeira, o estágio do espelho é o

[...] momento jubilatório da criança confrontada com sua própria imagem no espelho, quando ela, antes fundida e confundida com o mundo a seu redor, reconhece a própria imagem através da figura de um outro-eu. Dessa imagem, a criança, simultaneamente, percebe sua diferenciação em relação ao mundo externo e confirma, a partir de fora, a perfeição narcísica que a constitui como falo de sua mãe. (TEIXEIRA, 2005, p. 75).

Althusser estrutura uma concepção de sujeito contrária à noção de sujeito cartesiano que a filosofia moderna adotou e desenvolveu. Ele requisita uma dimensão simbólica, "o sujeito humano transcende seu verdadeiro estado de difusão ou descentração, e encontra uma imagem consoladoramente coerente de si, refletida no espelho de um discurso ideológico dominante." (TEIXEIRA, 2005, p. 75). Ou seja, para Althusser os indivíduos interpelados pela operação ideológica, transformados em sujeitos sociais, agem conforme a identificação que encontram nas ideologias existentes no discurso do outro. $\mathrm{O}$ sujeito, ao se deparar com a multiplicidade de discursos sociais que existem, é interpelado por um discurso que o posiciona enquanto sujeito discursivo.

Esse Sujeito pode se reconhecer na religião, por exemplo, enquanto aparelho que estrutura a interpelação dos indivíduos em sujeito sem nome, um Sujeito Único e absoluto, submetendo o sujeito ao Sujeito. Esse procedimento da ideologia fomenta o reconhecimento recíproco entre os sujeitos e o Sujeito. Assim, fica a garantia que tudo está em seu devido lugar, tudo ocorre bem na medida em que o sujeito está submetido ao reconhecimento universal e a ideologia aparece como algo que tomou distanciamento, portanto, sua operação fica encoberta para a maioria dos sujeitos. "A conduta concreta, material desta maioria não é mais que inscrição na vida das admiráveis palavras da sua oração: Assim seja!" (ALTHUSSER, 1980, p. 113). É nesse aspecto que reencontramos a regressão à ideologia no exato ponto 
que parecíamos sair dela. Segundo Žižek (1996), em Althusser, a fé religiosa não é apenas uma convicção interna, mas é a Igreja como instituição e seus rituais. Esta última, longe de ser uma simples externalização da crença íntima, representam os próprios mecanismos que as geram. Para Žižek,

Quando Althusser repete seguindo Pascal, "Aja como se acreditasse, rezes, ajoelhe-se e você acreditará, a fé chegará por si", ele delineia um complexo mecanismo reflexo de fundação "autopoiética" retroativa que excede em muito a afirmação reducionista da dependência da crença interna em relação ao comportamento externo. Ou seja, a lógica implícita dessa argumentação é: ajoelhe-se e você acreditará que se ajoelhou por causa de sua fé, isto é, o fato de você seguir o ritual é expressão/efeito de sua crença intima, ao ser executado o ritual “externo” gera sua própria base ideológica. (ŽIŽEK, 1996, p. 18).

Nesse exemplo, dado por Althusser e retomado por Žižek, podemos encontrar materialmente, na realidade social, a interpelação do sujeito, ou seja, o modo como a ideologia interpela o sujeito socialmente. Quando o sujeito crê ter se ajoelhado por causa da fé, simultaneamente se reconhece no chamado do Deus-Outro que determinou que se ajoelhasse. "Pois é a partir desse carater externo da máquina simbólica que podemos explicar o status do inconsciente como radicalmente externo - o de uma letra morta." (ŽIŽZEK, 1996, p. 321). A crença, nesse aspecto, é uma questão de obediência à letra morta e não compreendida, expondo uma espécie de curto-circuito entre a crença íntima e o que Žižek chama de "máquina externa" que impõe sua ordem, remetendo, assim, ao núcleo mais subversivo da teologia pascaliana.

A forma como a ideologia interpela o indivíduo transformando-o em sujeito é peça fundamental para a ação dos aparelhos ideológicos, esses só têm sua performance plenamente concretizada na medida que são aceitos livremente pelos sujeitos já capturados pela ideologia. No próximo tópico compreenderemos como funciona esse processo.

\section{O APARELHO DE ESTADO E O APARELHO IDEOLÓGICO}

Essa espécie de versão contemporânea da máquina pascalina é uma contribuição singular às perspectivas sobre ideologia desenvolvidas anteriormente, mas deixa um ponto em aberto, já que não consegue esgotar em profundidade o vínculo entre o AIE e a interpelação ideológica. A discussão gira em torno de compreender então como o AIE, enquanto máquina pascaliana, se internaliza produzindo o efeito da crença ideológica, numa relação de causa e efeito conector a do processo de subjetivação. Nesse caso, como acontece o reconhecimento da posição colocada pela interpelação?

Só podemos entender essa questão se buscarmos as respostas no essencial da teoria marxista do Estado. Segundo Althusser (1970), essa se expressa na compreensão de que o Estado e a existência do seu aparelho só têm sentido na função do poder de Estado. Toda a luta de classe gira ao redor da tomada e da conservação do poder de Estado, por uma certa classe ou pelas alianças desta. Assim, os clássicos do marxismo afirmaram:

1) o Estado é o aparelho repressivo de Estado; 2) é preciso distinguir o poder de Estado do aparelho de Estado; 3) o objetivo das lutas de classes visa o poder de Estado e, consequentemente, a utilização feita pelas classes (ou aliança de classes ou em frações de classes), detentoras do poder de Estado, do aparelho Estado e função dos seus objetivos de classe; 4) o proletariado deve tomar o poder de Estado para destruir o aparelho de Estado burguês existente, e, numa primeira fase, substituí-lo por um aparelho de Estado completamente diferente, proletário, depois em fase ulteriores, iniciar um processo radical, o da destruição do Estado. (ALTHUSSER, 1980, p. 38).

O filósofo procura ultrapassar a mera descrição do Estado e do aparelho de Estado para poder adentrar uma discussão que pressupõe essas categorias, mas procurando diferenciá-las em "poder de Estado" de "aparelho de Estado". O Estado define, de fato, a função fundamental do aparelho de Estado como a força de execução e de intervenção repressiva, a serviço da classe dominante. Define, assim, que o Estado é aparelho de Estado, não só aparelho especializado cuja existência e necessidade são 
reconhecidas a partir das exigências da prática jurídica, como da polícia e do exército, mas também como o governo e a administração.

Por sua vez, de modo recíproco, o aparelho de Estado como meio para consolidação do poder do Estado, compreende: o governo, a administração, o exército, a polícia, os tribunais, as prisões e tudo aquilo que funciona pela repressão e pela violência, incluindo a violência que se manifesta para além da forma física. O aparelho de Estado é repressivo e unificado, é um todo organizado cujas diferentes formas estão subordinadas a uma unidade de comando: o poder de Estado. Sua organização centralizada sob a direção dos representantes da classe dominante executa as políticas que amparam as dicotomias da luta de classe, que são em última análise relações de exploração.

O AE não atua de modo especializado, pertencendo inteiramente ao domínio público, mas a própria distinção entre o público e privado foi o objeto do direito burguês: "O Estado, que é o Estado da classe dominante, não é nem público nem privado, é pelo contrário, a condição de toda a distinção entre público e privado." (ALTHUSSER, 1980, p. 46). Em si mesmo, o Aparelho de Estado funciona de maneira massiva pela repressão e secundariamente pela ideologia, pois esses dois, Estado e Ideologia, nunca se desvinculam inteiramente. E justamente através da ideologia, a classe dominante que detém o poder do Estado consolida e assegura a harmonia entre aparelho repressivo de Estado e os Aparelhos Ideológicos de Estado. Por isso a necessidade de compreender o que Althusser designa como Aparelho Ideológico de Estado, "Um certo número de realidade que se apresenta ao observador imediato sob a forma de instituições distintas e especializadas." (ALTHUSSER, 1980, p. 43). E assim, ele atua de modo determinado em suas especificidades como nos casos,

[...] - O AIE religioso (o sistema das diferentes igrejas. - AIE escolar (o sistema das diferentes escolas públicas e particulares). - o AIE familiar. - O AIE jurídico. - O AIE político (o sistema político de que fazem parte os diferentes partidos). - O AIE sindical. - O AIE da informação (imprensa, radiotelevisão etc.). O AIE cultural (Letras, Belas Artes, desportos etc.). (ALTHUSSER, 1980, p. 44).

A pluralidade com que o AIE se manifesta é antagônica à unicidade do AE. Enquanto um é público o outro é privado, enquanto um é repressivo e violento, o AIE é obviamente ideológico. Esse não é só o alvo da luta de classes, mas o próprio lugar onde ela materialmente se manifesta. Essas duas dimensões não se descolam, por isso é imprescindível ressaltar que os dois tipos de aparelhos se combinam muito sutilmente para poder operar na vida cotidiana. Precisamos estar atentos, pois o jogo dos aparelhos constrói uma consonância precária, e essa ligação dialética em que cada um depende do outro para se manifestar e atuar socialmente enquanto negatividade pode e deve ser atacada. Segundo Žižek (1996), os AIE exercem sua força à medida que são vivenciados na economia inconsciente do sujeito, como injunção traumática e sem sentido. Para o filósofo esloveno,

\footnotetext{
Althusser fala apenas do processo de interpelação ideológica mediante o qual a máquina simbólica da ideologia é "internalizada", na experiência ideológica do Sentido e da Verdade: mas podemos aprender com Pascal que essa "internalização", por uma necessidade estrutural, nunca tem pleno sucesso, que há sempre um resíduo, um resto, uma mancha de irracionalidade e absurdo traumáticos que se agarram a ela, e que esse resto, longe de prejudicar a plena submissão do sujeito à ordem ideológica, é a própria condição dela: é precisamente esse excedente não integrado de trauma sem sentido que confere à Lei sua autoridade incondicional; em outras palavras, é ele que - na medida em que o eu escapa ao sentido ideológico - sustenta o que podemos chamar de jouissens ideológico, o gozo-no-sentido (enjoy-meat) que é próprio da ideologia.(ŽIŽEK, 1996, p. 321).
}

Žižek (1996) aponta, assim, que a própria lacuna que há entre a interpelação ideológica e a atuação dos AIE é exatamente o espaço para a consolidação da ideologia, esse espaço pode ser mais bem compreendido se aprofundarmos os estudos sobre os modelos de controle e manipulação com os quais outros filósofos compreenderam esse mesmo tema, por isso, se impõe a necessidade de conhecer os conceitos que trabalharemos a seguir. 


\section{O APARELHO, A POSITIVIDADE, O DISPOSITIVO E O “GRANDE OUTRO”}

O aparelho que Althusser apresenta é de grande originalidade e importância para a filosofia política e estudos sobre a ideologia. Ele opera materialmente, evidenciando como a ideologia se instaura na sociedade em mecanismos muito bem articulados que se colam à realidade de tal forma que se aparentam em perfeita naturalidade - ou se não, como necessidade premente que não pode ser substituída por outro mecanismo de controle.

Uma miríade de pensadores se aproximou do conceito de aparelho, de modo diferenciado. Assim, podem ser destacados: o conceito de dispositivo, amparado no pensamento de Foucault (2008) e Agamben (2009), a positividade, em Hegel e a noção de "grande Outro", em Lacan (1992). Todos esses filósofos procuraram investigar os mecanismos pelos quais a sociedade ganha uma determinada forma de manipulação arquitetada por meio de equipagens, agenciamentos, mecanismos, aparatos e outras tecnologias que operem as formas de coerção, subjetivação alienante e dessubjetivação. De modo diversificado, esse conjunto de conceitos contribui de forma significativa para a compreensão da ideologia. Mesmo que alguns desses autores, como no caso de Foucault, não usem o termo ideologia, o conceito é substituído por outros potencialmente capazes de explicar e compreender o fenômeno a partir de outras articulações, como é o caso do dispositivo. Assim, o conceito de dispositivo parece abarcar o conceito de ideologia, determinando o nosso interesse por ele.

Segundo Agamben (2009), o dispositivo é um termo técnico decisivo no pensamento de Foucault, e pode ser compreendido como um conjunto heterogêneo, linguístico e não linguístico, que inclui virtualmente qualquer coisa no mesmo título: discursos, instituições, edifícios, medidas policiais, proposições filosóficas etc. Ele tem sempre uma função estratégica concreta e se inscreve numa relação de poder e saber. "O dispositivo é a matriz da governamentalidade: é aquilo por meio do qual se realiza a pura atividade de governo sem nenhum fundamento no ser. Por isso, os dispositivos devem sempre implicar um processo de subjetivação, isto é, devem produzir o seu sujeito.” (AGAMBEN, 2009, p. 38). Pensando sobre governamentalidade, Isis Freitas (2016) afirma que:

O curso de Michel Foucault intitulado Segurança, território, população, proferido no Collège de France em 1977-1978, tem por marca fundamental o desenvolvimento de uma genealogia da governamentalidade moderna. No referido curso são apresentadas três formas de poder: o modelo do Estado territorial de soberania (o poder baseado na teoria da soberania, que é vinculada a uma forma de poder que se exerce sobre a terra e os produtos da terra, muito mais do que sobre os corpos e sobre o que eles fazem); o poder disciplinar (sociedade disciplinar), os dispositivos visam, através de uma série de práticas e de discursos, de saberes e de exercícios à criação de corpos dóceis, que se aplicam ao corpo por meio das técnicas de vigilância e de instituições punitivas) e o biopoder (estado de população contemporâneo - que captura a vida em sentido massificante e totalizante). (FREITAS, 2016, p. 62).

O conceito de "autotranscendência da sociedade", que é o dispositivo, foi tomado de Foucault, mas também demanda a noção hegeliana de "positividade" como ordem social substancial imposta ao sujeito e experimentada como destino externo e não como parte orgânica em si. A positividade é o nome dado por Hegel ao elemento histórico, com suas regras, ritos e instituições impostas ao indivíduo de modo exterior a ele, mas que se torna interna no sistema de crenças e sentimentos. O jovem Hegel (1971), no texto $A$ positividade da religião cristã, investiga os motivos da religião cristã ter se tornado autoritária, forjando, inclusive, uma aceitação política da escravidão, pois o homem aceitava a autoridade externa na legalidade e na heteronomia. É exatamente em exemplos históricos como esses que a positividade exprime um caráter de coação, de não liberdade, de heteronomia, contrário à razão, segundo o filósofo alemão.

Jean Hyppolite, pensador que teve forte influência sobre Foucault e a filosofia francesa, ensejou Foucault a desenvolver posteriormente o conceito de dispositivo, ora tomado por Agamben. Para Hyppolite (1971), o conceito de positividade na Introdução à filosofia da história de Hegel, tem seu lugar na oposição entre "religião natural" e "religião positiva", no qual a religião natural seria aquela próxima à natureza e não institucionalizada; a positiva, enquanto histórica, compreende o conjunto de crenças, regras e rituais que são impostos ao indivíduo pela exterioridade. Assim, essa religião positiva implicaria, 
segundo o próprio Hegel (1971), em sentimentos que são impressos na alma por meio de coerção e comportamentos que são resultados de relação de comando e obediência. Nesse sentido, a positividade funciona como uma articulação de manipulação ideológica ancorada na crença.

As intenções de Hegel (1971) e Foucault (1971) são claramente distintas. Hegel busca reconciliar os domínios da religião e da razão e assim procura desvendar a positivação. Foucault investiga os modos concretos pelos quais os dispositivos agem nas relações e jogos de poder. Ele se recusou a trabalhar com categorias gerais, ou universais, mas também admitimos que os dispositivos são precisamente a estratégia foucaultiana, não para falar de medidas de segurança isolada, de tecnologias de poder específicas, mas, sim, para remeter a um conjunto de práticas e mecanismos que constituem de modo urgente e imediato a subjetivação.

Para Agamben (2009), a noção de dispositivo tem origem na teologia da Providência Divina e se liga à oikonomia grega, implicando a relação de Deus com o mundo até o modo como Deus administra seu reino. Ele evidencia como um dispositivo é minimamente sagrado, de tal modo que, assim que um ser vivente é capturado por um dispositivo, ele é desapropriado de sua própria identidade enquanto sujeito. No entanto, os dispositivos ao longo do tempo vêm se remodelando, e esse mecanismo, segundo Agamben, passa a funcionar de modo múltiplo, como no caso das novas tecnologias. Os dispositivos tecnológicos, como celulares, tablets e aplicativos usados para todo tipo de finalidade, subjetivam fazendo uso de inteligência artificial, para colher dados e os adequarem às individualidades. Mas, ao mesmo tempo dessubjetivam, pois massificam as performances e docilizam corpos e mentes ao subjugo da tecnologia, fazendo dos sujeitos massa amorfa, ou verdadeiros zumbis fantasmáticos, sem autenticidade, esvaziados enquanto sujeitos, resultando em um "sujeito espectral". Nessas circunstâncias os dispositivos dessubjetivam sem produzir uma nova subjetividade:

\footnotetext{
Daqui surge o eclipse da política, que pressupunha sujeitos e identidades reais (o movimento operário, a burguesia etc.), e o triunfo da oikonomia, isto é, de uma pura atividade de governo que visa somente à sua própria reprodução. Direita esquerda, que se alternam hoje na gestão do poder, tem por isso bem pouco o que fazer com o contexto político do qual os termos provem e nomeia simplesmente os dois polos - aquele que aposta sem escrúpulos na dessubjetivação e aquele que gostaria, ao contrário, de recobri-la com a máscara hipócrita do bom cidadão democrático - de uma mesma máquina governamental. (AGAMBEN, 2009, p. 48-9).
}

Essa leitura de Agamben (2009) nos apresenta a compreensão de que entre os seres viventes e os dispositivos temos os sujeitos. Ou melhor, o que compreendemos como sujeitos é o resultado do "corpo a corpo entre os viventes e os dispositivos" (AGAMBEN, 2009, p. 41). Por isso que, contemporaneamente, o indivíduo pode ser o lugar de múltiplos processos de subjetivação. $\mathrm{O}$ que Agamben afirma é bastante semelhante à afirmação de Althusser: "a ideologia interpela indivíduos em sujeito" através de um aparelho. Essa interpelação do indivíduo como sujeito é a compreensão do indivíduo interpelado como um sujeito (livre) para que ele possa obedecer livremente às ordens daquele que formula sua sujeição, a fim de que tal sujeição seja aceita (livremente). Assim, esse sujeito passa a fazer os gestos e as ações de sua sujeição sozinho (de livre e espontânea vontade). Essa noção de sujeito nos remete a uma compreensão não ingênua da noção de sujeito e seu imbricamento com a ideologia. Assim, segundo Žižek,

Foucault, Althusser e Lacan insistem na ambiguidade crucial do termo "sujeito" (como agente livre e sujeitado do poder) - o sujeito enquanto agente livre surge por sua sujeição ao dispositif/AIE/ "grande Outro". Como afirma Agamben, a "dessubjetivação" e a subjetivação são dois lados da mesma moeda: é a própria dessubjetivação de um ser vivente, sua subjetivação

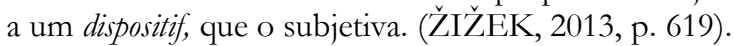

Paradoxalmente, na atualidade, a sofisticação desse processo, com a intensificação da administração e regulação da vida dos indivíduos, faz com que os dispositivos não gerem mais a interpelação do indivíduo em sujeito. Agamben (2009) chama a atenção para o fato de que, a medida que o cidadão é dessubjetivado, ele não se pergunta sobre os dispositivos hegemônicos da democracia contemporânea, ou seja, o sujeito burguês foi desapropriado dessa definição, ele não sabe o que é 
democracia. Os dispositivos são de tal forma articulados que os cidadãos têm suas vidas controladas até nos mais íntimos detalhes, e assim a própria passividade desses cidadãos coloca em suspensão a eficácia performativa desses dispositivos, fazendo essa máquina "girar em falso" e transformar-se, segundo Žižek (2013), em "uma autoparódia que não serve para nada".

De modo análogo, lembramos que o campo econômico concerne equivocadamente à esfera da não ideologia, ao ponto dos economistas se considerarem pós-ideológicos, pois em sua autopercepção pensam ter superado a ideologia. Como aqueles que se consideram fora da ideologia, parte deles sustentam o pensamento economicista a partir de um viés ultraliberal. Esse predomínio da esfera econômica pode parecer ausência de ideologia, mas agora, contrariamente, a economia, mais do que nunca, serve como modelo ideológico. "Assim, temos toda a razão de dizer que, aqui, a economia funciona como AIE, ao contrário da vida econômica "real", que definitivamente não segue o modelo idealizado pelo mercado liberal.” (ŽIŽEK, 2012, p. 301).

Nesse aspecto, para Althusser, os indivíduos são seres viventes sob os quais age o dispositivo/AIE, impondo-lhes uma série de práticas, ao passo que o sujeito não é uma categoria do ser vivente, da substância, mas o resultado das capturas desses seres viventes em um dispositivo/AIE. O problema é que, segundo Žižek,

Althusser falha em sua insistência desconcertante e deslocada na "materialidade" dos AIE: a forma primordial de dispositif, o "grande Outro" da instituição simbólica, é precisamente imaterial, uma ordem virtual - como tal, é correlativa do sujeito enquanto distinto do indivíduo na qualidade de ser vivente. Nem o sujeito nem o dispositif do grande Outro são categoriais do ser substancial. (ŽIŽEEK, 2013, p. 619).

A contribuição de Althusser para pensar a ideologia e a estruturação que ele faz desse pensamento é inestimável, mas do ponto de vista da materialidade parece ainda deixar o aparelho sem um fundamento seguro por falta de um avanço para a articulação com as categorias mais substanciais da psicanálise. Porém, no presente trabalho, a articulação com Hegel referente ao conceito de positividade, a ideia de dispositivo como conceito recorrente em Agamben e Foucault e o "grande Outro", de Lacan, são costuras importantes para uma compreensão mais profunda da ideologia, pois contribuem, de modo diferenciado, na abordagem do problema na interpelação do sujeito e na imbricação dos fatores inerentes à ideologia. Por isso que, ao nos apoiarmos na leitura do AIE, somada à leitura do conceito de dispositivo, conseguiremos uma compreensão mais densa da noção de ideologia. A propósito, Althusser é um autor que avança de modo crítico na ideia de ruptura com o aparelho ideológico de dominação que é a escola, buscando dar conta desse aparelho escolar de modo mais coerente e fornecendo, assim, uma análise para a contemporaneidade de como ela parece ainda ser espaço para a disseminação e materialização da ideologia. A este núcleo temático que damos prosseguimento ao próximo tópico.

\section{A ESCOLA COMO APARELHO IDEOLÓGICO}

Durante o período pré-capitalista existia um AIE dominante: a Igreja, que segundo Althusser (1980) concentrava não só as funções religiosas, mas também escolares e culturais. Por isso que, do século XVI ao século XVIII, principalmente com a Reforma Protestante, a luta ideológica foi anticlerical e antirreligiosa. A Revolução Francesa também colaborou para o ataque à Igreja enquanto AIE, e modificou o funcionamento do aparelho de Estado ao propiciar a passagem do poder da aristocracia feudal para a burguesia capitalista-comercial. Assim foi quebrado um determinado tipo de aparelho repressivo de estado que foi substituído por outros. O desenrolar da luta de classe durante o século XIX levou a aristocracia fundiária e a burguesia industrial a ocuparem as funções que outrora eram exclusivas da Igreja, e o lugar encontrado para consolidar e estruturar esse poder foi a Escola. Nesse sentido, a função que era realizada pelo duo Igreja-família foi substituída pelo duo Escola-família. "O AIE que foi colocado em posição dominante nas formações capitalistas maduras, após uma violenta luta de classes política e ideológica contra o antigo aparelho Ideológico de Estado dominante, é o Aparelho Ideológico escolar." (ALTHUSSER, 1980, p. 60). 
As relações de exploração e dominação capitalistas são resultantes da incidência de todos os tipos de AIE em seu conjunto, mas a escola desempenha papel dominante, segundo Althusser (1980), embora, paradoxalmente, nem sempre se dê a essa dominação muita atenção, pois atua, como toda ideologia, de modo silencioso. A escola, de modo opaco, é a base da aprendizagem disseminada pela ideologia, é nela onde se colocam todas as crianças de classes sociais distintas, durante os anos mais vulneráveis da infância, e ensinam-lhes a ideologia dominante. Isso acontece através dos saberes práticos: línguas, cálculos, história, ciências, literatura, ou simplesmente empurrando a ideologia dominante em seu estado mais puro: moral, instrução cívica e doutrinação político-religiosa.

Como se trata de um aparelho que dispõe durante muito tempo de audiência obrigatória de parte considerável da sociedade, através das crianças, a ideologia dominante chega à família como um todo. A escola domina de forma magistral as crianças, pois tem de cinco a seis dias por semana de presença na vida delas. Um pouco maiores, adolescentes se jogam no mundo do trabalho, tornando-se mão de obra barata. Outra parte, mais reduzida, de juventude escolarizável, continua no sistema educativo para assumir postos da pequena burguesia. E, assim, uma parte consideravelmente pequena de jovens consegue empregos razoáveis, enquanto a maioria cai no semiemprego, ou ainda, como hoje, no desemprego. A propósito como destaca Althusser,

Cada massa que fica pelo caminho está praticamente recheada da ideologia que convém ao papel que ela deve desempenhar na sociedade de classes: papel de explorado (com consciencia profissional, moral, cívica, nacional e apolítica altamente desenvolvida); papel de agente da exploração (saber mandar e falar aos operários: as relações humanas), de agentes da repressão (saber mandar e ser obedecido sem discussão ou saber manejar a demagogia retórica dos dirigentes políticos), ou profissionais da ideologia ( que saibam tratar as consciências como respeito, isto é, com o desprezo, a chantagem a demagogia que convêm, acomodados às sutilezas da Moral, da Virtude, da Transcendência, da Nação, do papel da França no mundo, etc). (ALTHUSSER, 1980, p. 66).

A ideologia que a escola dissimula, de modo naturalizado e palatável, reproduz o regime capitalista. É através das aprendizagens de saberes práticos disseminados em aulas que é inculcado de forma massiva a ideologia da classe dominante. Nesse processo, enquanto uma ideologia que representa a Escola como um meio neutro desprovido de ideologia, esta escola dissimula exatamente a ideologia que se diz não ideológica. Na escola burguesa que funciona como AIE, os mestres, supostamente respeitosos da consciência e da liberdade das crianças que lhes são confiadas pelos pais, fazem ascender os alunos à liberdade, à moralidade e à responsabilidade de adultos pelo seu próprio exemplo, pelos conhecimentos, pela literatura e pelas suas virtudes. Mas todo esse discurso da escola reproduz somente as relações de produção com base em uma formação social capitalista.

Os professores colaboram de tal forma com essa sistemática, e estão tão submersos na ideologia quanto qualquer outro ser vivente que não colocam em dúvida o funcionamento da escola. Sem se dar conta de tal processo, os educadores contribuem pelo seu empenho em manter a representação ideológica da Escola que a torna natural, indispensável, útil e benfeitora, tanto quanto era a Igreja anteriormente. O AIE escolar coopta os professores e por meio da representação ideológica a escola se descola de sua construção histórica material feita pelos homens, e aparece como qualquer outro fenômeno ideológico, inclusive para os professores. No entanto, Althusser situa os professores ao fazer a seguinte reflexão:

Peço desculpas aos professores que, em condições terríveis, tentam voltar-se contra a ideologia, contra o sistema e contra as práticas em que este os encerra, as armas que podem encontrar na história e no saber que ensinam. Em certa medida são heróis. Mas são raros, e quantos (a maioria) não tem sequer um vislumbre de dúvida quanto ao trabalho que o sistema (que os ultrapassa e esmaga) os obriga a fazer, pior, dedicam-se inteiramente e com toda a consciência à realização desse trabalho. (ALTHUSSER, 1980, p. 67-68).

A profunda crise que o sistema escolar e familiar sofre, adquire um sentido político se considerarmos que a escola constitui o AIE dominante, "aparelho que desempenha um papel determinante na reprodução das relações de produção de um modo de produção ameaçado na sua 
existencia pela luta de classes mundial." (ALTHUSSER, 1980, p. 68). Ou seja, a escola ensina a reproduzir o modo operante do capitalismo que está em luta de classe permanente. Conforme reproduz a luta de classes, a escola e a família estão, em si, sempre em crise, pois não funcionam plenamente com vistas à emancipação humana, mas simplesmente para a reprodução das relações de produção capitalistas (ALTHUSSER, 2008).

A escola participa de modo determinante do processo de consolidação do sujeito. O domínio em que a interpelação do indivíduo em sujeito acontece através da ideologia, a escola coaduna e participa enquanto aparelho para a articulação e implementação desse processo. A escola do século XXI adotou as performances empresariais e o modelo de reprodução econômica neoliberal. O poder do aparelho escolar se potencializa operando em consonância com a ordem econômica vigente, na qual a economia também é ideológica.

$\mathrm{Na}$ contemporaneidade a escola passou a ser uma empresa e como qualquer outra corporação econômica que visa o "mais valor". O compromisso, portanto, é com o mercado e não com a formação de sujeitos livres. Sob esse prisma é visada a formação de empreendedores que se desumanizam e dessubjetivam. Os jovens hoje, como Althusser já apontou no passado, passam a ter compromisso com a exploração, a precarização e a exclusão do ser humano, pois é isto em o que AIE escolar/econômico se transformou. Prolifera uma era de escolas voltadas inteiramente para atender o mercado mundial, de acordo com os interesses de grandes corporações econômicas. Esses são os valores da escola que podemos chamar de neoliberal, em que os valores econômicos estão acima do bem coletivo, essa escola entende a educação como um bem privado.

[...] não é a sociedade que garante o direito à cultura a seus membros; são os indivíduos que devem capitalizar recursos privados cujo rendimento futuro será garantido pela sociedade. Essa privatização é um fenômeno que atinge tanto o sentido do saber e as instituições que supostamente transmitem os valores e os conhecimentos quanto o próprio vínculo social. À afirmação da plena autônima dos indivíduos sem amarras, salvo as que eles próprios reconhecem por vontade própria, correspondem instituições que parecem não ter outra razão de ser que não seja servir a interesses particulares. (LAVAL, 2019, p. 16).

No Brasil, a síntese do aparelho escolar com o econômico se mostra ainda mais evidente quando, durante o governo iniciado em 2019, aplicaram-se reformas educacionais cada vez mais subservientes à dominação do aparelho econômico ultraliberal internacional. Segundo Laval (2019), o sistema de educação no Brasil é muito mais "neoliberalizado" do que muitos sistemas europeus. A reforma do ensino médio, Lei $\mathrm{N}^{\mathrm{o}}$ 13.415, implementada em fevereiro de 2017, prolifera atualmente a perspectiva da escola como AIE, associada ao modelo do empresariamento das relações, assim como a aplicação do projeto "Future-se" no ensino superior.

A breve apresentação que o Ministério da Educação faz em seu site traz informações que demonstram apenas o gerenciamento mercadológico ao qual as universidades devem se submeter.

1. O que é o Future-se? O Future-se busca o fortalecimento da autonomia administrativa, financeira e da gestão das universidades e institutos federais. Essas ações serão desenvolvidas por meio de parcerias com organizações sociais. O programa se divide em três eixos. 2. Quais são três eixos?

Gestão, Governança e Empreendedorismo. Promover a sustentabilidade financeira, ao estabelecer limite de gasto com pessoal nas universidades e institutos — hoje, em média, 85\% do orçamento das instituições são destinados para isso; estabelecer requisitos de transparência, auditoria externa e "compliance"; criar ranking das instituições com prêmio para as mais eficientes nos gastos; gestão imobiliária: estimular o uso de imóveis da União e arrecadar por meio de contratos de cessão de uso, concessão, fundo de investimento e parcerias públicoprivadas (PPPs); propiciar os meios para que departamentos de universidades/institutos arrecadem recursos próprios, estimulando o compartilhamento de conhecimento e experiências entre eles; autorizar "naming rights" (ter o nome de empresas/patrocinadores e patronos na instituição) nos campi e em edifícios, o que possibilitaria a manutenção e modernização dos equipamentos com apoio do setor privado. Pesquisa e Inovação instalar centros de pesquisa e inovação, bem como parques tecnológicos; assegurar ambiente de negócios favorável à criação e consolidação de startups, ou seja, de empresas com base tecnológica; aproximar as instituições 
das empresas, para facilitar o acesso a recursos privados de quem tiver ideias de pesquisa e desenvolvimento; premiar os principais projetos inovadores, com destaque para universidades e institutos que tiverem melhor desempenho, respeitada as condições inicias e especificidades de cada um. Internacionalização: estimular intercâmbio de estudantes e professores, com foco na pesquisa aplicada; revalidação de títulos e diplomas estrangeiros por instituições públicas e privadas com alto desempenho, de acordo com critérios do MEC; facilitar o acesso e a promoção de disciplinas em plataformas online; firmar parcerias com instituições privadas para promover publicações de periódicos fora do país; possibilitar bolsas para estudantes brasileiros com alto desempenho acadêmico e atlético em instituições estrangeiras. (MEC. Disponível em: http://www.mec.gov.br/future-se. Acesso em: 29 de setembro de 2019).

Não cabe aqui fazer uma exposição delongada sobre o Future-se, mas se vê contemplado o incentivo a investimentos privados nas universidades públicas, o que em longo prazo visa restringir o acesso à universidade àqueles que podem pagar por ela, consolidando assim o processo de privatização desta instituição. O discurso empreendedor e tecnicista chega com força à universidade para fomentar a formação de profissionais voltados exclusivamente para o mercado de trabalho, desconsiderando o investimento em pesquisa e desenvolvimento científico que não esteja imediatamente ligado ao interesse do capital. Pesquisas de longo prazo não são consideradas como algo produtivo. Essa forma de proceder, segundo o entendimento do governo, ataca de modo contundente às ciências humanas e sociais como aquelas que não contribuem, inclusive, atrapalham o processo de desenvolvimento econômico, causando dispêndio à sociedade e, portanto, devem ser eliminadas.

A reforma do Ensino médio também atende aos interesses de um aparelho ideológico que impõe o interesse econômico acima do escolar, pois acaba com a obrigatoriedade das múltiplas disciplinas regulares que conhecemos, tornando somente língua portuguesa, matemática e língua inglesa disciplinas regulares durante os três anos dessa etapa de ensino. Abre-se, nesse sentido, um espaço para áreas de conhecimento genéricas, nas quais podem atuar profissionais de "notório saber". Segundo a Lei, "Profissionais com notório saber reconhecido pelos respectivos sistemas de ensino, para ministrar conteúdos de áreas afins à formação ou experiência profissional, atestados por titulação específica ou prática de ensino em unidades educacionais.” (Lei 13.415, Art. $5^{\circ}$, parágrafo IV).

O aumento da carga horária do Ensino contempla a chamada educação integral, o que em tese parece ser interessante do ponto de vista da consolidação do conhecimento, mas não leva em conta a estrutura das escolas, as diferenças regionais, ou mesmo a vida cotidiana do jovem trabalhador em idade escolar, fazendo com que essa seja uma reforma que atende principalmente o interesse da classe dominante. Segundo a Lei, "A carga horária minima anual deverá ser ampliada de forma progressiva, no ensino médio, para mil e quatrocentas horas, devendo os sistemas de ensino oferecer, no prazo máximo de cinco anos, pelo menos mil horas anuais de cargo horária, a partir de 02 de março de 2017." (Lei $\left.13.425, \$ 1^{\circ}\right)$. Nesse sentido, o ensino médio na sua totalidade chegará a 4.200 horas, das quais 1.800 serão de Base Nacional Comum Curricular (BNCC) e o restante, 2.400 ou mais, de conteúdo diversificado. Tal modelamento de horas faz com que os alunos recebam mais conteúdos de formação específica do que daquilo que é conteúdo básico para o ensino, nesse contexto a formação básica voltada para a crítica e emancipação humana ficam extremamente dilaceradas, pois contarão com pouquíssimas horas.

Tais mudanças, que não levam em consideração as diversas demandas da média de $80 \%$ dos jovens brasileiros que estudam nas escolas públicas, preconizam que a totalidade dos estudantes concorra a exames para o acesso ao ensino superior. Enquanto as famílias que podem pagar escolas particulares, nas quais seus filhos serão treinados para o ENEM (Exame Nacional do Ensino médio o qual a nota é requisito para acesso ao ensino superior), serão aquelas cujos filhos terão acesso à educação nas melhores universidades. Para as escolas públicas, onde está a maior parte da juventude empobrecida, profissionais de "notório saber" poderão dar aulas para a formação de mão de obra técnica, que no contexto da reforma trabalhista é inteiramente precarizada. Para os muitos jovens trabalhadores o ensino à distância é oferecido, mas só como meio de falsear o ensino.

A educação ofertada àqueles sujeitos que mais precisam de formação para superar sua condição de preconceito de classe faz com que esses permaneçam propositalmente aprisionados na mesma condição. Daí o falseamento do ensino, já que apesar das mentes articularem um discurso de melhoria de ensino, na verdade pretendem que os alunos cercados por dispositivos de controle e coerção 
tenham acesso à plataformas de ensino, mediante o acesso a computador e internet, mas os alunos não têm acesso a essas ferramentas. A opção, assim, são estudos domiciliares, proposta essa ainda em discussão. Esses são métodos tecnológicos dessubjetivantes, que usam dispositivos e aparelhos de enquadramento que esvaziam as possibilidades reais de interação e conhecimento transformador, portanto, impedindo a possibilidade real de mudança das condições de vida dessas, a não ser em casos excepcionais em que serão usados pelas mentes que pensam a educação como exemplos de meritocracia, fortalecendo a ideia perversa de "empresariamento de si". Ainda referente ao debate sobre estudos domiciliares, ele ganha espaço dentro das famílias tradicionais arrebanhadas pelas igrejas neopentecostais que defendem essa modalidade de ensino, levantando a bandeira de um liberalismo conservador, diante dos interesses moralistas que defendem.

Sobre o tema da educação básica e os dispositivos de ensino/controle incidem grandes conglomerados e grupos educacionais com suas editoras e sistemas de ensino prontos para serem vendidos. Laval (2019) afirma que o Brasil foi um dos primeiros países do mundo a chegar ao que ele chama de "capitalismo escolar e universitário". O domínio massivo de empresas gigantes cotadas na bolsa de valores, como o grupo Kroton, Estácio, Anhanguera, com mais de 1,5 milhão de estudantes expõe como a educação é tratada, principalmente no Brasil. "O neoliberalismo escolar resultou, na verdadeira guerra entre classes para entrar nas "boas escolas" de um sistema escolar e universitário cada vez mais hierarquizado e desigual.” (LAVAL, 2019, p. 13).

Em pouco tempo poderemos ver a oferta de profissionais de educação tanto à distância quanto em serviços terceirizados para escolas e famílias. Assim, aplicando a lógica empresarial do lucro e da competitividade, ofertam o serviço mais barato ao ganho mais extraordinário, portanto, nem sempre presando pela qualidade do ensino e humanização do serviço prestado. Nesse contexto, podemos ter aulas de baixa qualidade para os alunos da rede pública e um novo modelo de educação domiciliar para a classe abastada, baseado na cobrança de altos valores por serviços prestados individualmente a esses estudantes privilegiados financeiramente.

Com relação a esse mesmo tema no Brasil, não podemos renunciar às reflexões que Severino (Rio Claro, 1941) faz da condição da educação em nossa sociedade principalmente no que diz respieto a ideologia (SEVERINO, 1986). Segundo ele, o modo operante que ela se encontra é atualmente de perfil assumidamente neoliberal. Caracterizada "com expressões no plano cultural, com sua exacerbação do individualismo, do produtivísmo, do consumismo, da indústria cultural, da mercadorização até mesmo dos bens simbólicos, não instaura nenhuma pós-modernidade." (SEVERINO, 2000, s.p.). Quer dizer, a forma como nossa sociedade se organiza e, portanto, constrói o processo educativo está embebido nos processos ideológicos que o capitalismo impõe desde a modernidade. Para o autor brasileiro, não chegamos à pós-modernidade, pois na sociedade ainda se aprofunda a maturação das premissas e promessas da própria modernidade. "Nada mais moderno do que esta tecnicização, viabilizada pela revolução informacional. Finalmente, a modernidade está realizando as promessas embutidas em seu projeto civilizatório. Nada mais moderno do que o individualismo egoísta dos dias de hoje." (SEVERINO, 2000, s.p.).

Severino nos alerta que é preciso não perder de vista a historicidade da existência humana, que fica encoberta pelo refinado processo ideológico de que o fim das utopias do progresso humano possa significar igualmente o fim da história (SEVERINO, 2000). E a realidade do contexto histórico latino-americano é marcado pela exclusão humana de seus diretos. Assim, é necessário observar com bravura que a atual situação do Brasil no séc. XXI desmente a ideia de que já se teria encontrado o caminho certo para a construção de uma sociedade amadurecida, justa e democrática. Para Severino:

O processo de modernização pelo qual passou e continua passando o continente está acontecendo a um preço muito alto. A organização econômica, de lastro capitalista, sob um clima político de mandonismo interno das elites nacionais e da dominação externa dos grupos internacionais, impõe uma configuração socioeconômica na qual as condições de vida da imensa maioria da população continuam extremamente precárias. Na verdade, o aclamado processo de globalização da economia parece universalizar as vantagens do capital produtivo e as desvantagens do trabalho assalariado. Dada essa situação, o conhecimento, em geral, e a educação, em particular, são interpelados com relação a seu papel histórico. O quadro da 
realidade social e educacional do Brasil mostra bem o quanto a existência histórica dos brasileiros está longe de atingir um patamar mínimo de qualidade. Mostra também o quanto é ainda grave o déficit educacional em termos quantitativos e qualitativos e como é ainda grande o desafio para os gestores da educação no Brasil. Exigem-se deles uma avaliação mais crítica da situação real da nossa sociedade e uma maior vigilância diante do mavioso canto das sereias do neoliberalismo.(SEVERINO, 2000, s.p.)

Ao que tudo indica, até agora a educação não é a alavanca que possibilita a transformação da sociedade, pois está ainda sob as demandas exclusivas da formação econômica capitalista, como alertou Althusser, a escola é aparelho ideológico, e agora aliada ao aparelho econômico. Então devemos estar atentos para como podemos agir na transformação desse aparelho.

\section{CONSIDERAÇÕES FINAIS}

Althusser foi classificado como estruturalista por fazer análises do funcionamento básico de toda ideologia como um sistema que envolve quatro instâncias: 1) a interpelação dos indivíduos concretos enquanto sujeitos; 2) a sujeição destes indivíduos ao Sujeito; 3) o reconhecimento mútuo entre os sujeitos e o Sujeito, o reconhecimento dos sujeitos entre si e finalmente o reconhecimento do sujeito por si mesmo; 4) a garantia absoluta de que tudo é realmente assim, e sob a condição de que os sujeitos reconheçam o que são e se comportem como tal tudo correrá bem: amém - assim seja. (ALTHUSSER, 1980).

Tal compreensão traz implícita a dimensão de que a interpelação ideológica e a sua conexão com os AIE, em especial o escolar, não pode renunciar à fórmula lacaniana da fantasia. Ou seja, mais uma vez, esse curto-circuito, esta lacuna entre esses dois fenômenos, tão fundamentais à implementação da ideologia, tem como pedra de toque o espaço onde a fantasia se apresenta. Althusser (1970) apontou este espaço lateralmente quando desenvolveu a tese de que a "a ideologia é uma 'representação' da relação imaginária dos indivíduos com suas condições reais de existência”. Porém, isso por si só não é suficiente para explicar como tal fenômeno se manifesta materialmente, por se tratar de uma explicação baseada em idealismos, por isso ele aponta a interpelação como ponto de conexão, para a instrumentalização dos AIE que estão em relação dialética com a própria interpelação. O que Althusser não contava é que aí ainda restava um espaço não explicado onde a fantasia atua. Assim Žižek nos lembra que:

Essa é a dimensão desconsiderada na explicação althusseriana da interpelação: antes de ser captado na identificação, no reconhecimento/desconhecimento simbólico, o sujeito (\$) é captado pelo Outro através de um paradoxal objeto-causa do desejo em meio a isso, (a), mediante o segredo supostamente oculto no Outro: $\$ \nabla_{a}$ - a formula lacaniana da fantasia. Que significa mais exatamente, dizer que a fantasia ideologica estrutura a própria realidade? Expliquemos isso partindo da tese lacaniana fundamental de que, na oposição entre sonho e a realidade, a fantasia fica do lado da realidade: ela é, como certa vez disse Lacan, o suporte que dá coerência ao que chamamos "realidade". (ŽIŽZEK, 1996, p. 323).

Por isso que já no início dessa exposição procuramos mostrar que a ideologia não é uma ilusão, muito menos uma ilusão do tipo onírica. Para nossa compreensão, a ideologia é uma construção da fantasia que serve de esteio à nossa realidade. Uma ilusão no sentido que estrutura nossas relações sociais reais e efetivas, e que, por isso, mascara o insuportável núcleo real impossível; sua função sob este aspecto não é fornecer um escape à realidade, mas a própria realidade como fuga do núcleo real traumático. Retomando aqui a posição de Althusser, cabe apontar para aquilo que nela é o mais relevante:

Toda ideologia representa, na sua deformação necessariamente imaginária, não as relações de produção existentes, mas antes de mais nada a relação imaginária dos indivíduos com as relações de produção e com as relações que delas derivam. Na ideologia, o que é representado não é sistema das relações reais que governam a existência dos indivíduos, mas a relação imaginária destes indivíduos com a relações reais em que vivem. (ALTHUSSER, 1980, p. 82). 
Para Žižek (1996), a fantasia é pensada dentro da ideologia, pois a fantasia é tanto aquilo que encobre as inconsistências dentro da ordem simbólica quanto aquilo que permite a interpelação ideológica na nossa época aparentemente pós-ideológica. É por meio dessa aparente distância da ideologia que a fantasia captura a subjetividade. Sempre há uma lacuna entre o discurso público e seu suporte fantasmático. Longe de ser uma fraqueza secundária, ou sinal de imperfeição do poder, essa cisão é constitutiva de seu exercício. O fato é que não existe realidade sem o espectro (fantasia) de que o círculo da realidade só pode ser fechado por meio de um suplemento espectral estranho.

Outra limitação em Althusser, para além da falta de um vínculo profundo da ideologia com a materialidade, é questionar, no caso da crítica contundente aos aparelhos de Estado, aos aparelhos repressivos e ideológicos, e todos os aparelhos em geral, e sua derrocada: como organizar a sociedade? A perspectiva que o autor fornece coloca em xeque todas as formas de organização institucional e a formatação das relações econômicas sem trazer nenhuma perspectiva ou apontamento do que fazer caso acabemos com os aparelhos. Permanece em sua leitura uma atitude niilista ultrapassada. No cenário apresentado por Althusser, como fica a organização do corpo social e político da sociedade? Sem instituições, que são todas repressivas e ideológicas, como nos organizarmos? Não há superação do aparelho, criticamos ele, a escola e todas as instituições de maneira muito justa e profícua, mas como nos organizaremos? Precisamos de organização? Educação? Todo esse aparato só está a serviço da escola burguesa? Todas essas questões ficam em aberto nas leituras de Althusser. Alguns anos depois autores vão respondê-las, como Bourdieu no caso da educação e outros pensadores sobre a ideologia em geral, mas propriamente em Althusser não encontramos respostas.

A respeito da educação e a escola, em particular, precisamos estar permanentemente atentos ao aparelho e dispositivo que ela se constitui no Estado burguês, mas entendemos que a instituição escolar necessita persistir como local de aprendizagem da cultura, da ciência e da cidadania. A escola precisa estar alinhada, em primeiro plano, à lógica da emancipação humana e da formação de seres pensantes capazes de compreender a ideologia a que a escola, inclusive, está submetida. Tensionando essa visão para que o estudante se torne o sujeito do processo de conhecimento, construiremos uma abordagem plena de acontecimentos e que precisa estar permanentemente em transformação, pois nunca é completo, como o sujeito também nunca é. A educação como um todos deve desmascarar e aguçar a consciência das contradições sociais, contribuindo para sua superação na realidade objetiva. "Ela pode ser também elemento gerador de novas formas de concepções de mundo capazes de se contraporem à concepção de mundo dominante em determinado contexto sociocultural.” (SEVERINO, 2000, s.p.)

A escola não pode ser suprimida da sociedade, mas precisa exatamente persistir como ponto de viragem da compreensão alienada da sociedade. Ela precisa ser a condição de vida, que compreende a ideologia de forma para além da ingenuidade. A escola necessita ser um espaço garantidor da autonomia, inclusive em relação AIE que a família e a economia são, visto que estes aparatos podem coagir principalmente a infância e juventude. Compreender como a ideologia funciona e incide sobre a educação e a escola permite, inclusive, ao próprio estudante transformar a escola em direção a um ato de superação dos problemas sociais que enfrenta cotidianamente.

\section{REFERÊNCIAS}

ALTHUSSER, Louis. A corrente subterrânea do materialismo do encontro. Revista Crítica Marxista, Rio de Janeiro: Revan, n.20, p. 9-48, 2005.

ALTHUSSER, Louis. A favor de Marx. 2. ed. Rio de Janeiro: Zahar, 1979

ALTHUSSER, Louis. Freud e Lacan - Marx e Freud. 4.. ed. Rio de Janeiro: Graal, 2000.

ALTHUSSER, Louis. Ideologia e Aparelhos Ideológicos de Estado. 3. ed. Tradução Joaquim José de Maura Ramos. Lisboa: Presença/Martins Fontes, 1980.

ALTHUSSER, Louis. Sobre a reprodução. Petrópolis: Vozes, 2008. 
AGAMBEN, Giorgio. "O que é um dispositivo?” In: O que é o contemporâneo? E outros ensaios. Chapecó: Argos, 2009.

FOUCAULT, Michel. Segurança, Território e População. Curso no Collège de France (1977-1978). Tradução Eduardo Brandão. São Paulo: Martins Fontes, 2008.

HEGEL, George Wilhelm Friederich. História de Jesus. Tradução (castelhano) Santiago Gonzalez Noriega. Madrid: Taurus, 1975.

HYPPOLITE, Jean. Introdução à Filosofia da História de Hegel. Tradução Hamílcar Garcia. Rio de Janeiro: Editora Civilização Brasileira, 1971.

LACAN, Jacques. O estádio do espelho como formador da função do eu. In: Escritos. Rio de Janeiro: Zahar, 1998.

LACAN, Jacques. O Seminário, Livro 17: O Avesso da Psicanálise. Tradução Ari Roitman, Rio de Janeiro: Jorge Zahar Editor, 1992.

LACAN, Jacques. O Simbólico, o Imaginário e o Real (1953). In: Em Nomes-do-Pai. Rio de Janeiro: Jorge Zahar, 2005.

LAVAL, Christian. A escola não é uma empresa: o neoliberalismo em ataque ao ensino público. São Paulo: Boitempo, 2019.

MARX, ENGELS. A Ideologia Alemã. São Paulo: Boitempo, 2007.

MEC. Future-se. Disponível em: <http://www.mec.gov.br/future-se>. Acesso em: 29 set. de 2019.

FREITAS, Isis. Por uma genealogia da governamentalidade em M. Foucault e G. Agamben. Profanações, Ano 3, n. 1, p. 58-77, jan./jul. 2016. Disponível em: < http://webcache.googleusercontent.com/search?q=cache:r7IlVYy8CqwJ:www.periodicos.unc.br/inde x.php/prof/article/view/1167/658+\&cd=1\&hl=pt-BR\&ct=clnk\&gl=br > . Acesso em: 15 out. 2019.

SEVERINO, Antonio Joaquim. Educação, ideologia e contra-ideologia. São Paulo, EPU, 1986.

SEVERINO, Antonio Joaquim. Educação, trabalho e cidadania: a educação brasileira e desafio da formação humana no atual cenário histórico. São Paulo Perspec. São

Paulo, vol.14 no.2 Apr./June 2000.

SILVA, Renata. Linguagem e ideologia: embates teóricos. Linguagem em (Dis)curso - LemD, v. 9, n. 1, p. 157-180, jan./abr. 2009. Dispónível em: < http://www.scielo.br/pdf/ld/v9n1/a08v9n1.pdf $>$. Acesso em: 02 jun. 2019.

SLOTERDIJK, Peter. Crítica da razão cínica. São Paulo: Estação Liberdade, 2012.

TEIXEIRA, Marlene. Análise de discurso e psicanálise: elementos para uma abordagem do sentido no discurso. Porto Alegre: EDIPUCRS, 2005.

ŽIŽEK, Slavoj. A Visão em Paralaxe. São Paulo, Boitempo, 2008.

ŽIŽEK, Slavoj. Menos que Nada. São Paulo: Boitempo, 2013.

ŽIZŽEK, Slavoj. (Org.). Um mapa da Ideologia. Rio de Janeiro: Contraponto, 1996.

ŽIŽEK, Slavoj. Vivendo no fim dos tempos. São Paulo: Boitempo, 2012.

Submetido: $16 / 12 / 2019$

Aprovado: $17 / 07 / 2020$ 